\title{
Does Competitive Intelligence Matter? An Anthropological Way of Thinking
}

\author{
Camilla H. Wang \\ Shantou University \\ Luis A, J, Borges \\ Saint Xavier University
}

Competitive intelligence (CI) has become a very important part of business decision-makers. With the increase of globalization, mergers, and fragmentation top managers have to take into consideration this topic in their strategic planning. Besides, there are important links of competitive intelligence with knowledge management and anthropology. The reason of these links is based on the fact of the growing importance of these two disciplines in current business environment owing to the growth of information technology and diversity. Knowledge Management encompasses many common practices already in business since the identification of a problem, or a set of problems, up to the adoption of solutions by individuals who participate in the business processes. On the other hand, business anthropology deals with the before mentioned participants with their contributions with the Competitive Intelligence staff in the attempt to design a Knowledge Management program to protect their competitive advantages. This paper discusses the implementation of anthropology and knowledge management in a competitive intelligence situation. The authors will define what competitive intelligence is and will look at the links that connect an anthropological perspective followed by a discussion of cross cultural strategy applied with Knowledge Management in Competitive Intelligence decision-making practices.

\section{INTRODUCTION}

In order to face recent challenges, owing to the intense competition worldwide, competitive intelligence (CI) is a very important issue for strategic planning. The global competitiveness is a fact, and it is growing. The technology and communications are available everywhere. The Internet caused a great impact in the McLuhan "global village". When companies face strategic options they must rely on their intelligence.

Knowledge management $(\mathrm{KM})$ is another key function that companies recently start to pay attention to. $\mathrm{KM}$ implies to manage knowledge by using techniques and methods that were developed as part of Knowledge Technology to analyze the knowledge sources in an organization. Using these techniques one can perform Knowledge Analysis and Knowledge Planning.

Business leaders implementing competitive intelligence programs needs to have people to collect, store, and analyze information. Anthropologists will be the best candidates for CI staff to consider for collaboration, and anthropological methods will be the best solution for CI staff to broaden their ways of conducting CI programs. This paper discusses the implementations of anthropology in competitive 
intelligence and knowledge management. It starts with a definition of competitive intelligence with a literature review following a discussion of cross cultural strategy applied with Knowledge Management in Competitive Intelligence decision-making practices.

\section{What is Competitive Intelligence?}

The Society of Competitive Intelligence Professionals (SCIP) defined Competitive Intelligence as a systematic and ethical process for gathering and analyzing information about the competition's activities and general business trends to further a business's own goals (Davis,2011). However there was a change of names of the society to Strategic and Competitive Intelligence Professionals, with the same acronym, and the new website defines that Competitive Intelligence (CI) is a necessary, ethical business discipline for decision making based on understanding the competitive environment (SCIP website, 2012).

The pace of technological development and the growth of global trade mean that the business environment is changing very fast. Companies cannot afford to rely on instinct or intuition when making strategic business decisions. In many industries, the consequence of making one wrong decision may be to see the company go out of business. The price paid for not changing is too high. Research shows that competitive intelligence increases management's strategic planning "comfort level."(SCIP website, 2012) The significance of CI has kept growing in most business firms and the demanding for conducting more qualified CI programs is far more beyond the capacity of CI staff at individual business organizations.

Brody (2008) states that there are many issues in defining CI and the predominance of definitions or descriptions indicate a process. Considering that most of the literature addresses practice or analysis, process definitions seem to be the logical output. Therefore, it is suggested that CI is a "body of varying practices, as opposed to a body of practice and process; as a body of knowing, a body of practicing, or a body of acting rather than a body of knowledge".

Moreover, it can be said that $\mathrm{CI}$ is about making the organization more competitive relative to its existing set of competitors and potential competitors. Prescott \& Davis (1989) state that there are three basic objectives of a CI program: (a) to provide a general understanding of the industry and its competitors, (b) to identify areas of vulnerability and to assess the impact strategic actions would have on competitors, and (c) to identify potential moves of the competitors.

According to Egan (2001) CI can enhance profitability and develop or extend a competitive advantage over rivals. CI can shape decisions about market entry, product development, pricing, customer relations, mergers and acquisitions, and other vital areas that contribute to an organization's overall profitability and competitive profile.

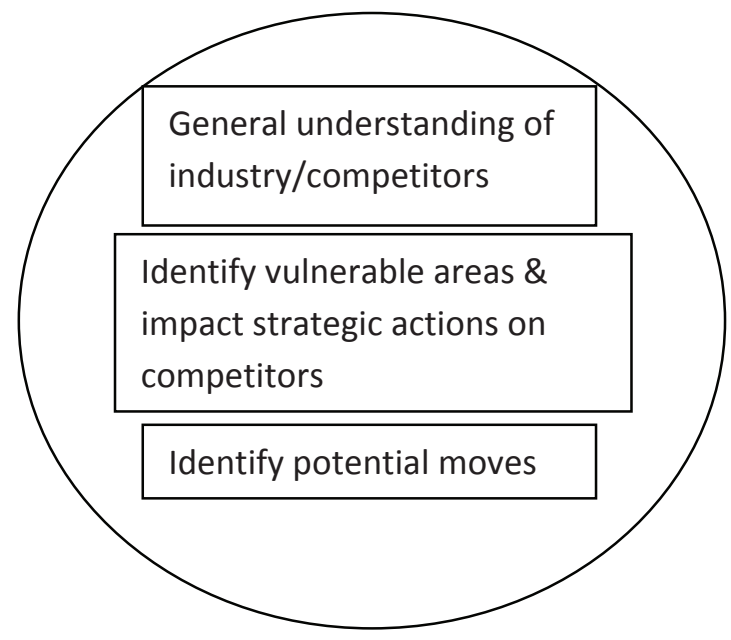

Figure 1. Basic Objectives of a CI program, according to Prescott \& Davis. 
Kahaner (2012) state that CI has become the latest weapon in the world war of economics among countries. While the major powers are moving away from traditional weapons of destruction, they are moving towards economic weapons like competitive intelligence to ensure their national sovereignty and survival. And going to the level of companies against companies.

Accepting the importance of competitive intelligence, major multinational corporations, such as ExxonMobil, Procter \& Gamble, and Johnson and Johnson have created formal CI units. Organizations execute competitive intelligence activities not only as a safeguard to protect against market threats and changes, but also as a method for finding new opportunities and trends.

Consider a 2001 marketing case study presented by Clifford Kalb, former SCIP president, and vice president of strategic business analysis at the pharmaceutical firm Merck \& Co., Inc. According to Mr. Kalb (and as reported in CI Magazine, Jan./Feb 2002), Merck's CI group was responsible for developing a counterstrategy to a competitor's forthcoming product rollout that, over a period of 30 months has enabled Merck to "anticipate and outmaneuver the competition," and resulted in "saving approximately \$200 million to the bottom line -- so far." And the estimated boost to the bottom line could go as high as $\$ 400$ million (SCIP website 2012).

To sum up, one can say that Competitive Intelligence is an ethical and legal business practice, and it is not the same as industrial espionage which is both unethical and usually illegal (SCIP website 2012). The focus is on the external business environment, and there is a process involved in gathering information, converting it into intelligence and then utilizing this in business decision making. CI professionals emphasize that if the intelligence gathered is not usable (or actionable) then it is not intelligence.

\section{What should be the difference from other fields?}

Competitive intelligence has some overlapping characteristics with some other fields in business, such as knowledge management, business intelligence, market intelligence, and marketing research. There is a common body of knowledge and a unique set of applied tools make CI clearly different, and that while other sensory activities in the commercial firm focus on one category of players in the market (such as customers, suppliers, or acquisition targets), CI is the only integrative discipline calling for a synthesis of the data on all High Impact Players (Gilad \& Herring, 2001).

According to Gilad (2008), Intelligence is a perspective on facts, not the facts themselves. Uniquely among other corporate functions, competitive intelligence has a specific perspective of external risks and opportunities to the firm's overall performance, and as such it is part of an organization's risk management activity, not information activities.

Competitive intelligence reaches more the external facts of the organization, than Business Inteligence, and Knowledge management. CI draws on a wider variety of sources, from a wider range of stakeholders, and seeks not just to answer existing questions but also to raise new ones and to guide action, than Market Research. There are some distinctions between CI and Strategic Intelligence, CI and Tactical Intelligence, and CI and Market Intelligence, which have basically internal focuses (Fleischer, 2003).

\section{The Process}

The intelligence process consists of four major parts: (i) decide what questions need to be answered; (ii) gather and process relevant information; (iii) analyze the information relative to the questions to be answered; and (iv) disseminate the results to the people who need it (Graef, 1993).

The fundamental process of competitive intelligence is gathering information. For example, companies will gather information about a similar product or group of products offered by competitors, encompassing all components of the products as possible, in order to see the similarities and differences of a given product in a given market.

This type of information can help in creating a market campaign, since it can factually demonstrate how products differ, and knowing to avoid some undesirable side effects in your product. Along with gathering intelligence on a competing product, the process of competitive intelligence may also look to the distribution network used to get the product to the consumer market. (Tatum, 2003). 


\section{Competitive Intelligence vs. Anthropological Approach}

Galvin (2001) states that Motorola opened up the Japanese electronic market and the Japanese respected it by using power from the US government, and they responded by purchasing Motorola products. That's an anthropological principle, and a very significant piece of intelligence (Galvin, 2001)

Anthropologists have created a discipline to make sense out of human behavior through the culture concept, a holistic approach, and empirical research. Its concepts have been defined largely in academia, and many of them work in several areas such as health care, education, business, marketing, and industry, mainly in the use of anthropological methods in competitive intelligence and marketing research.

Walle (2001) states that competitive intelligence is the information gathering and information analysis component of building competitive advantage. Although competitive intelligence and contemporary marketing research evolved from different intellectual and quantitative traditions, both are indebted to qualitative methods of research and analysis that anthropologists are well trained for. Nonetheless, the quantitative methodology has dominated in the competitive intelligence (CI) and marketing research (MR) area.

Walle discusses how the field of CI brings powerful qualitative tools to business research and argues that in an era when many business scholars and practitioners have come to depend upon mostly quantitative techniques, CI professionals have long embraced a qualitative, subjective, and intuitive toolkit that has provided timely meaningful information for many successful cases. But the vital role of anthropological qualitative methods within business strategy, particularly within CI and MR has been long neglected or ignored. He indicates that in the post-World War II era, when business research became more quantitative oriented, CI started with a qualitative method that drew inferences without formal proof; as a result, the field has gained a special niche within business. CI embraced the intuitive tools of ethnography and how marketing researchers have turned to the techniques of the qualitative social sciences and the humanities. He claims that CI can and should forge linkages between these two qualitative traditions.
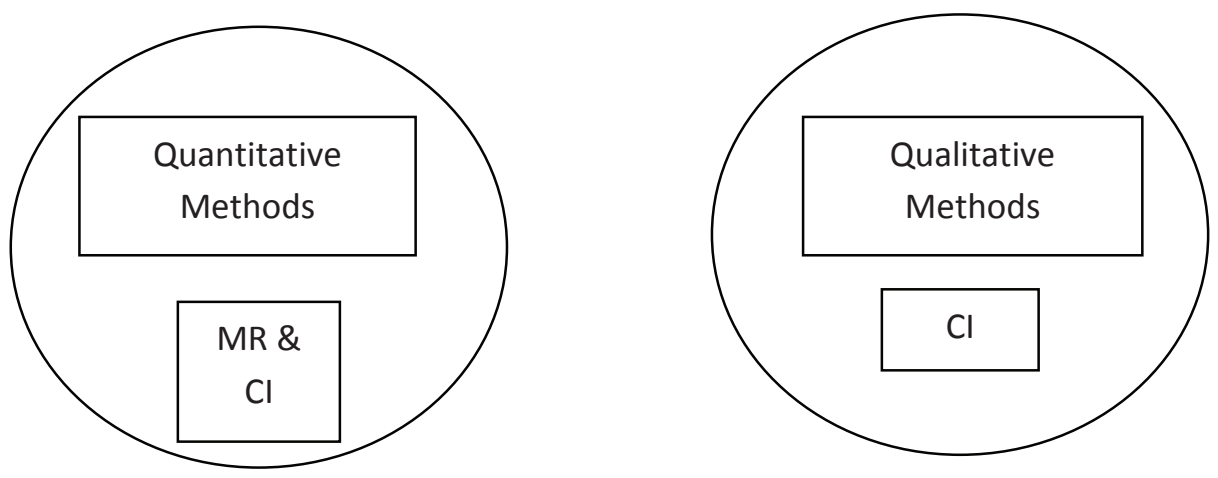

\section{Figure 2. Marketing Research and Competitive Intelligence domains}

Walle presents the current contemporary initiatives within business that link the methods of the social sciences and humanities to business analysis by making a well-reasoned rationale for CI professionals to apply qualitative methods in their business analysis. To Walle CI is qualitative in nature, a discipline that is based on the traditions of espionage, and thus has special toolkit, which is an argument that other CI professionals may disagree. The contemporary business world has elevated marketing theory and methods to a strategic position although much traditional business thought was centered upon management and had dealt with marketing as tactic subordinate activity. The intelligence profession has a strong tradition of embracing relevant aspects of the social sciences and humanities in its toolkit.

Recently many anthropologists involve themselves into MR although not many are yet involved in the CI field. Meanwhile more and more marketers are using anthropological methods in their marketing 
practice and research. In practice, business anthropologists almost study everything from marketing strategies to the corporate climate, applying traditional anthropological methods of research and observation to understand and reflect business culture, and thus make their contributions to the business development.

Anthropology's main distinguishing method is participant observation. Traditionally one is most familiar with anthropologists in their role as observers of various cultures. They study these by paying close attention to symbols, rituals, and myths or stories. Understanding the meanings behind these manifestations of culture enable anthropologists to understand the way in which different people view the world. Thus the anthropologist sees how culture directs and guides human behavior. Hofstede (1980) defines culture as the collective programming of the mind, which distinguishes the members of one group or category of people from another. Each group has a distinctive way in which it operates, even though it is part of a larger division and organization, or, anthropologically speaking, a clan and tribe.

According to Simon and Grzelak (2001), CI professionals can benefit from anthropological approach by viewing the organization not through their own eyes, but through the eyes of their clients, the individuals to whom they are rendering service. The CI manager should strive to view his or her client's needs as the client presents them, using only the client's myths, symbols, and rituals to clarify them. Understanding the client's values (and beliefs about 'the way' business should be done) provides the CI manager with a better opportunity to interact with that client. The more the client feels understood, the more familiar the relationship will feel to both the client and the CI manager -- and the more likely the client is to participate with the CI effort and to accept and adopt its offerings.

Hofstede (1980) describes three types of artifacts that CI professionals can quickly recognize in order to come to an understanding of the CI client's culture: Symbols, Rituals, and Myths. All of them are included in the organization's culture. Rafaeli \& Orline (1999) states that the first function of symbols is that members make meaning from them. Looking at obvious physical manifestations of an organization can tell us more than we might suppose. Trice and Beyer $(1984,1985,1993)$ described rites and ceremonials as discrete enactments that have a beginning and an end and give expression to a culture's values and beliefs. The CI staff that is able to participate in these rituals and also understand what they mean to their clients to become more socially accepted part of their client's organization. This process is important if the CI operative is able to move from an outsider to an insider. For business anthropologists, myths are the stories about the individuals that the client considers important as their heroes. The characteristics of the heroes help the CI professionals to understand what the client values in its members.

Organizational heroes such as Henry Ford, Bill Gates, or Motorola's Robert Galvin all have significant meanings to their companies. Recognizing the types of individuals that succeed within the client's culture tells CI managers how to best present themselves to the client. Again, this knowledge will help the CI professional seem more familiar to the client, and thereby become more accepted and trusted by the client (Simon \& Grzelak, 2001).

The corporate of internal culture defined by internal factors of influences must be supportive. These factors include management preferences, organizational structure, and resources that affect CI initiatives. It affects how information is collected and what information is collected. Equally important is an external culture that supports CI efforts. By exploring the external factors of influence such as political, social, and economic factors, a business firm can draw conclusions of a country's CI friendliness. Certain environments are more conductive to CI practices because these external factors allow practitioners to access information easily (Kahaner, 1996).

Toczydlowski (2005) says that Ethics has been an important issue among CI practitioners. Essentially, the questions revolve around what is and is not allowable in terms of CI practitioners' activity. A number of very excellent scholarly treatments have been generated on this topic, most prominently addressed through Society of Competitive Intelligence Professionals publications. The concept of espionage is very strong and delicate in that field. 


\section{Competitive Intelligence, Knowledge Management, and Anthropology}

Competitive intelligence, as was said before with gathering data, then managing and deploying knowledge systematically within the organization. Increasingly, knowledge is recognized as a key organizational asset, to be leveraged and exploited for competitive purposes. As such knowledge management becomes one of the hottest topics today in both the industry world and information research world (McLellan, 2001).

Gray (2010) states that support management in the decision-making process is the main role of CI. The process may ensure marketplace competitiveness through legal means, and requires understanding the external environment and individual competitors. It works to protect your organization against your competitor's CI. In performing it, you can use whatever you find in the public domain, your own internal data, purchased data, and analyses.

In our daily life, we deal with huge amount of data and information. Data and information is not knowledge until we know how the value out of it. This is the reason we need knowledge management. Unfortunately, there is no universal definition of knowledge management, just as there is no agreement as to what constitutes knowledge in the first place.

Toczydlowski (2005) ponders that a Knowledge Management system must organize the intellectual assets of a corporation, with recorded information, corporate experience, third-party information, and tacit knowledge of employees. KM is a newly emerging, interdisciplinary business model dealing with all aspects of knowledge within the context of the organization, including knowledge creation, codification, sharing, protection, and how these activities promote learning and innovation.

KM efforts include on-the-job discussions, formal apprenticeship, discussion forums, corporate libraries, professional training and mentoring programs. Large companies and non-profit organizations have resources dedicated to internal KM efforts, often as a part of their business strategy, information technology, or human resource management departments (Addicott et al., 2006). More recently, with increased use of computers in the second half of the 20th century, specific adaptations of technologies such as knowledge bases, expert systems, knowledge repositories, group decision support systems, intranets and computer supported cooperative work have been introduced to further enhance such efforts.

In practice, KM encompasses both technological tools and organizational routines in overlapping parts. It efforts typically focus on organizational objectives such as improved performance, competitive advantage, innovation, the sharing of lessons learned, and continuous improvement of the organization. These efforts can be better operated with the help of anthropologists.

What does anthropology have or do that is of value to Knowledge Management? Burke (1998) developed an anthropological model to knowledge management indicating that anthropologists are interested in how knowledge is constituted by different people and how knowledge is managed in terms of how it is secured and deployed. Understanding KM in an organizational context brings anthropology together with a number of other disciplines such as psychology, business theory and information modeling. This can enhance our understanding while simultaneously creating new forms of organizational

knowledge.

The main method for Anthropology is participant observation, involving the anthropologist spending a protracted period doing fieldwork in an effort to gain an in-depth understanding of the society under study. Anthropology can make significant contributions to the implementation of KM. According to Burke (1998), observing employees going about their day-to-day tasks is an important way of externalizing tacit knowledge is just one of the ways in which anthropology can make a significant contribution to the implementation of KM.

Burke (1998) argues that at its most simple, people are observed going about their daily tasks, routines and decision-making processes. The observer is required to note everything, with the aim ultimately of reconstructing the categories and operating frameworks of those being observed. This tends to throw up a host of ethical and practical issues, not least how to observe without getting in the way or unduly influencing behaviors. The end result is a creative reconstruction that is validated by use of other research methods in the fieldwork situation and by checking premises and explanations with informants. 
According to Burke (1998), the continual drive towards classification in order to unravel, or recreate, the implicit internal logic of naming systems is important. Anthropological tools are valuable to provide a useful starting point of assist in this process. They can provide a generic classification and set of definitions covering such areas as organization structures, strategies and skills based on common management theory and practice. Ideas and values, and tacit knowledge are often seen as the cohesive agents that bind an organization as a single entity. This is a common premise underlying both the concept of organizational culture and the belief that this can be affected in various ways to bring about desired change. Although many organizations have accumulated detailed information, with vast databases containing the history of customer transactions over many years, much of an organization's knowledge is tacit and cannot readily be stored in more traditional information repositories. Can and should tacit knowledge be made more explicit? Is it possible to take personal knowledge and transform it into a corporate intellectual asset? (Burke, 1998). Some of the key issues include costs involved in objectifying or commoditizing knowledge versus the benefits to be gained, mechanisms for rewarding or compensating individuals for transferring such knowledge and issues of validation and truth (Burke, 1998).

What becomes interesting, useful and proper to know? What limits are places on investigation, experimentation, diffusion and reception? How do topics and discourses become authorized, constructed, regulated, supervised and subverted? Are questions to be asked, according to (Burke, 1998). Some of these questions are not only pertinent in relation to organizations, but are manifest in the debates currently raging across the Internet and in Knowledge Management conferences, which are attempting to define standards and norms for Knowledge Management. To some extent, Knowledge Management itself may involve a process of ironing out differences and so become a form of conflict resolution.

It is important to know other aspects, such as personal knowledge, intellectual assets, Sustainable Advantage, the Enabling Workspace, and Linking Processes. Many questions should be asked to analyze the key processes with the four components that constitute the knowledge space. They include knowledge preservation processes, Information Management processes, ownership and governance, processes for innovation and personal development processes (Burke (1998).

\section{Conclusion}

In order to answer the main question: Does Competitive Intelligence Matter? It did for Galvin 2001) at Motorola, and it is likely that grasping and conveying anthropological knowledge will fall to intelligence department as we expand our awareness of this very complex, multi-faced world.

Gardner (2001) publishes that Some big companies have entire departments devoted to gathering competitive intelligence. Paul Scharfman, founder and CEO of Specialty Cheese Co. in Wisconsin, eschews online research and focuses on letting every employee and customer know that he values tips they pass on to him. "The more people who know you care, the more information you're going to get," he says.

The Nature Biotechnolgy (2000) publishes that according to a 1993 survey by the Conference Board, $5 \%$ of US multinational firms and $9 \%$ of European multinational firms have complete competitive intelligence systems embedded in their operations. This is not much, but the data are from 1993.

The 2011 Global Intelligence Survey by the Global Intelligence Alliance (GIA) revealed that, in spite of the economy, nearly $70 \%$ of North American companies plan to increase their budgets for competitive intelligence in 2012. Of these, $94 \%$ agree that they have benefited from competitive intelligence; $42 \%$ without a competitive intelligence operation intend to launch one within 12 months; and $69 \%$ plan to increase their investments into competitive intelligence over the next two years (Miller, 2011).

It does matter, even that still many companies misuse or underuse according to Rumore, and Stoehr (2005): "In what is arguably the most competitive global marketplace in history, a surprisingly high number of companies do not consider intelligence for strategic reasons, to assess competition or to devise operational plans for their businesses," said Kenneth Sawka, a principal at Outward Insights. "And for those companies that have an organized CI function, these systems tend to be ineffective or underdeveloped." 


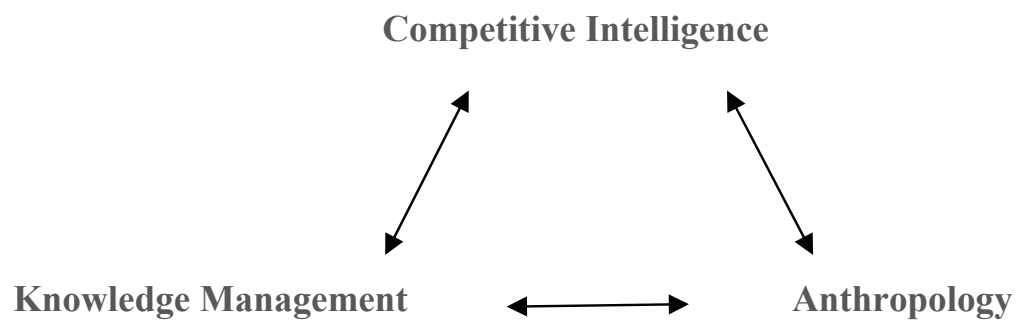

Fig 3. Competitive Intelligence, Knowledge Management and Anthropology Relationships

Figure 3 depicts a representation of the relationships among Competitive Intelligence, Knowledge Management and Anthropology. In order to get Competitive Intelligence organizations must rely in several aspects of Anthropology, as well as of Knowledge Management. Besides, there is a connection between the last two disciplines.

Due to the rapidly changed contemporary business environments competitive intelligence and knowledge management become two of most growing fields in the business world. Every business manager needs intelligence to find suppliers, mobilize capital, win customers and fend off rivals. All these require CI staff must broaden their ways of collecting, storing, analyzing information to meet the need of business leaders for competitive intelligence. In the same way, CI must rely in the workers involved in the process, with their culture, symbols, rituals, and myths, and everyday more diversified populations.

\section{REFERENCES}

Addicott, R., McGivern, G. \& Ferlie, E. (2006), "Networks, Organizational Learning and Knowledge Management: NHS Cancer Networks", Public Money \& Management 26 (2): pp. 87-94, avilable at SSRN: http://papers.ssrn.com/sol3/papers.cfm?abstract id=889992, retrieved in April, 2012.

Brody, R. (2008) Issues in Defining Competitive Intelligence: An Exploration. Journal of Competitive Intelligence and Management, 4 (3): 3-16

Burke, P., (1998), An Anthropological Approach, Inside knowledge, posted 1 Sep 1998, 2 (1) http://www.ikmagazine.com/xq/asp/sid.0/articleid.27D8703A-FB17-4753-8C5B7E4F0C236A71/eTitle.An Anthropological Approach/qx/display.htm, retrieved in April, 2012

Galvin, Robert W. (2001). "Competitive Intelligence at Motorola", in John E. Prescott and Stephen H. Miller (Eds.) Proven Strategies Competitive Intelligence: Lessons from Trenches. Wiley, John and Sons.

Gardner, J. (2001). Competitive Intelligence on a Shoestring, Inc., 09/21/2001, http://www.inc.com/articles/2001/09/23436.html, retrireved in May, 2012.

Gilad, Ben (2001). "Industry Risk Management: CI's Next Step", Competitive Intelligence Magazine, 4 (3), May-June.

Gilad, Ben (2008). "The Future of Competitive Intelligence: Contest for the Profession's Soul", Competitive Intelligence Magazine, 2008, 11(5), Haag, Stephen (2006). Management Information Systems for the Information Age. Third Edition. McGraw-Hill Ryerson.

Gilad, Ben and Jan Herring. "CI Certification - Do We Need It?", Competitive Intelligence Magazine, 2001, 4(2), 28-31.

Graef, J. (1993), Competitive intelligence: how and where to find it, May. http://www.montague.com/le/le5934.html retrieved April 2012.

Gray, P. (2010), Competitive Intelligence, Business Intelligence Journal, 15 (4): 31-37

Hofstede, G. (1980). Cultures Consequences: International Differences in Work-related values. London: Beverly Hills.

Kahaner, L. From Black Ops to Boardrooms--How Businesses Gather, Analyze, and Use Information to Succeed in the Global Marketplace. http://www.kahaner.com/ci.shtml retrieved Apri, 2012 
McLellan, Hilary (2001). "Introduction to Competitive Intelligence", http://www.saratogamedia.net/ CI2004/cintell.htm, retrieved in July, 2009

Miller, G. (2011). Online Retailers Will Spend More \$\$ On Competitive Intelligence in 2012, Upstream Commerce, posted on November 19, 2011, http://upstreamcommerce.com/blog/2011/11/19/ north-american-companies-spend-big-on-competitive-intelligence-2012, retrieved in May, 2012.

Nature Biotechnology (2000) Competitive business intelligence gathering and analysis, Nature Biotechnology 18, IT5 - IT6.

Prescott, J. \& Smith, D., The Largest Survey of 'Leading Edge" Competitor Intelligence Managers". Planning Review 17 (3) (May-June 1989):6-13

Rafaeli, A. \& Orline, M. (1999) Symbols in Organization Culture, http://iew3.technion.ac.il/ Home/Users/anatr/symbol.html, retrieved in May, 2012

Rumore, Danielle and Stoehr, Donna (2005). U.S. Corporations Misuse or Underuse Competitive Intelligence, Outward Insights Survey Shows; Naive 'Ostriches' Misjudge Importance, Necessity of CI in Global Marketplace, New York Times (Business Wire), Feb 16, 2005.

SCIP website http://www.scip.org/resources/content.cfm?itemnumber=601\&nav ItemNumber=533 retrieved in April 2012.

Simon, N. \& Grzelak, D. (2001). "Business anthropology: clues to culture", SCIP, Society of Competitive Intelligence Professionals, Vol. 04 No. 04, July - August

Tatum, Malcolm (2003) "What is Competitive Intelligence?" http://www.wisegeek.com/what-iscompetitive-intelligence.htm, retrieved in July, 2009.

Toczydlowski, Betty (2005). "Knowledge, Skills, and Abilities of Domestic and International Competitive Intelligence Practitioners". In Blenkhorn, David and Craig S. Fleisher (Eds.) Competitive Inteeligence and Global Business. Greenwood Publishing Group.

Trice, H. M., \& Beyer, J. (1984). Studying organizational cultures through rites and ceremonials. Academy of Management Review, 9, 653-669.

Trice, H. M., \& Beyer, J. (1985). Using six organizational rites to change cultures. In R. H. Kilmann, M. J. Saxton, \& R. Serpa (Eds.), Gaining control of the corporate culture (pp. 370-399). San Francisco: Jossey-Bass.

Trice, H. M., \& Beyer, J. (1993). The cultures of work organizations. Englewood Cliffs, NJ: Prentice Hall.

Walle, Alf H. III (2001). Qualitative Research in Intelligence and Marketing. Westport, CT: Quorum Books 